\title{
Preamble: EAPR 2017: a Real International Success!
}

\section{Michel Martin ${ }^{1}$}

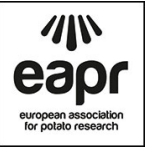

Published online: 10 March 2018

(C) European Association for Potato Research 2018

With more than 440 participants of 49 nationalities, coming from 5 continents, the 20th Triennial Conference of the European Association for Potato Research, held at the Palais des Congrès of Versailles from 9 to 14 July 2017, was undeniably an international success, a success not only because of its attendance

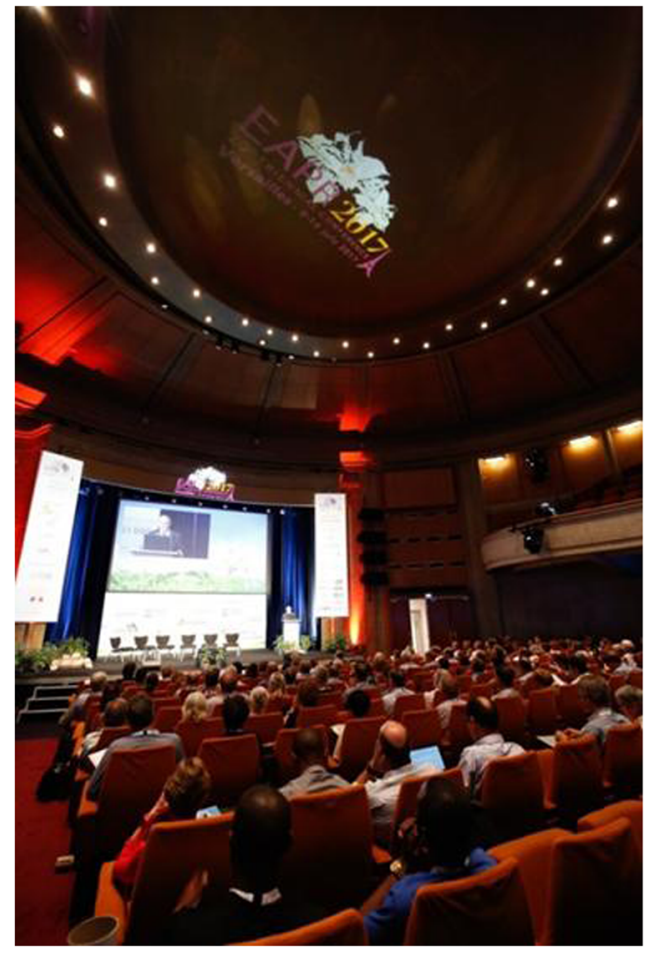

Michel Martin

m.martin@arvalis.fr

1 ARVALIS-Institut du végétal, Estrees Mons, France 
but also because of the quality of the scientific programme: more than 300 papers distributed over 14 plenary sessions, 24 parallel sessions, 3 workshops and 2 poster sessions.

It was the third time that France organised a Triennial Conference of the EAPR. After Brest in 1969 and Paris in 1993, it was an honour for France to welcome the delegates of the European Association and the worldwide community of scientists working on potato research and innovation in Versailles, a place of exception (Fig. 1). On this location, some 330 years ago, the very first marketing actions for the development of potato production in France took place, launched by the famous French pharmacist Antoine-Augustin Parmentier. Versailles was also an appropriate and spectacular place to celebrate the 60th birthday of the EAPR, created in Lund (Sweden) in 1957.

The conference was organised by ARVALIS-Institut du végétal with the support of the inter-professional organisations of the entire French potato sector (CNIPT, GIPT and GNIS-FN3PT) and with the collaboration of the French National Institute for Agricultural Research (INRA). Their efforts were completed by a national scientific committee composed of members from various French scientific and technical institutions and/or private companies including ARVALIS-Institut du végétal, INRA, FN3PT, SIPRE and GERMICOPA. The national scientific team was supported by an International Scientific Committee of 50 renowned scientists, covering the different topics to be developed during the conference, in order to review the 300 submitted abstracts.

Undoubtedly, this 20th edition of the Triennial Conferences of the EAPR will leave an excellent memory to the delegates who came to share the results of their recent work, from breeding to the valuation of products, through all the components inherent to the techniques of multiplication and production (Fig. 2).

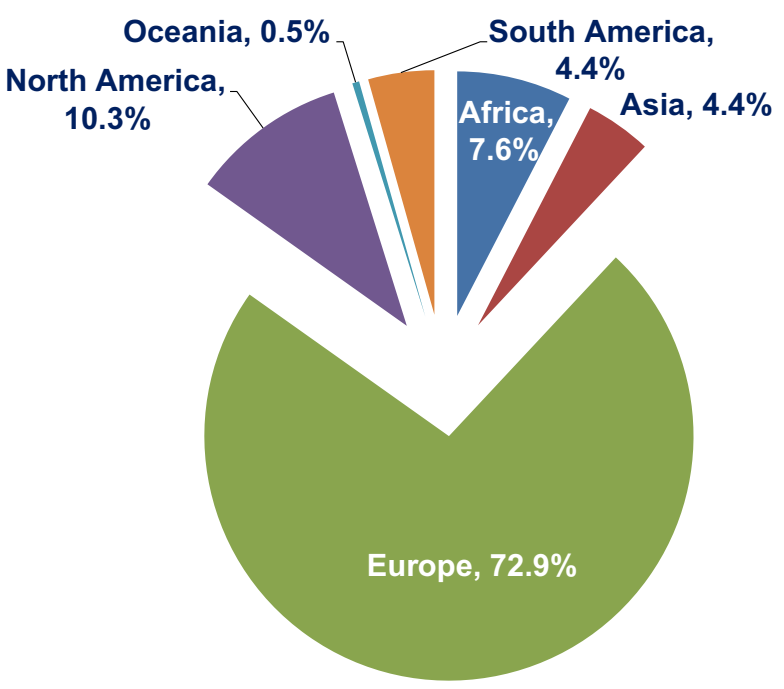

Fig. 1 Origin of the participants of the EAPR 2017 Conference 


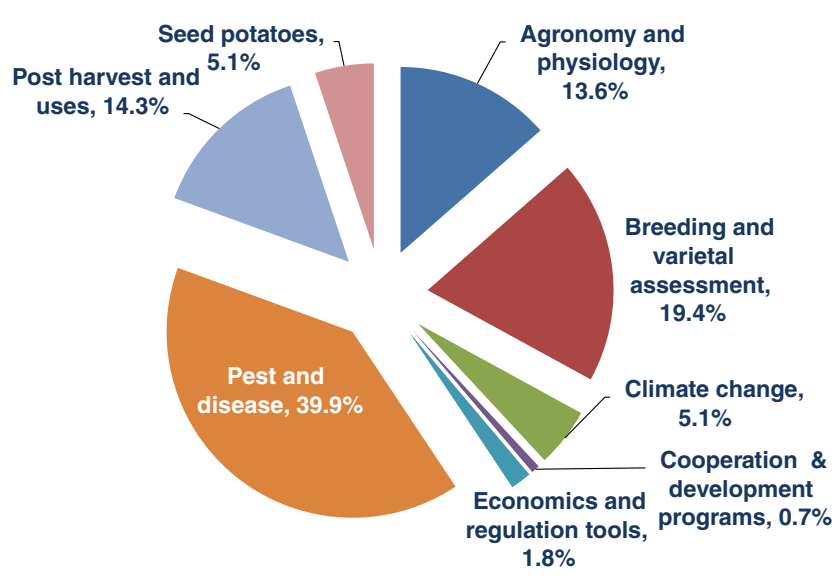

Fig. 2 Distribution of the accepted abstracts at EAPR 2017 over the main topics of the conference

The various oral and poster presentations laid many bricks and stones to try to meet the slogan of the event: "Potato facing global challenges".

As the acreage and total production of potato are increasing globally, showing how the crop is becoming more and more vital to feed the world (now, potato is the third food crop most consumed by humans in the world after rice and wheat), different challenges are arising. The crop needs to cope with climate change with implications for increased sensitivity to biotic and abiotic stresses and with newly emerging pests and diseases and increasing aggressiveness of certain pathogens; farmers need to consider environmental and societal issues, such as producing potato without pesticides, improving the nutritional value of tubers, etc.

Regarding these issues, the conference was flagged with the slogan "Potato facing global challenges" and the presentations were distributed over plenary sessions, parallel sessions, workshops and poster sessions in order to cover the aim of the conference to provide sustainable solutions or promising leads into their direction.

The following pages of this issue of the scientific journal of the Association "Potato Research" group the papers of the invited keynotes given during the plenary sessions of the 20th triennial EAPR Conference and offer a good overview of the current "state-of-the-art", the main advances achieved and the main issues investigated by the potato scientific community to realise these objectives during the coming years!

As an opening for more cooperation between the global research teams, two workshops ("Biocontrol and bio-stimulant agents for the potato crop" and "Research-Industry partnership for the benefit of the potato sector") were organised within the framework of the CIP-EAPR action plan. They show the right direction for further concrete and collaborative actions to be pursued. The third workshop, titled "Seed potatoes research challenges", was managed by the UMT Innoplant (FN3PT-INRA) on another very pertinent topic for the whole industry worldwide. 
The attractiveness of the conference was important to the 49 young scientists who submitted an abstract for the EAPR Student Support Contest. Finally, 24 $\mathrm{PhD}$ students from 19 countries were selected to receive a grant thanks to the direct support of the EAPR, completed with actions of CNIPT.

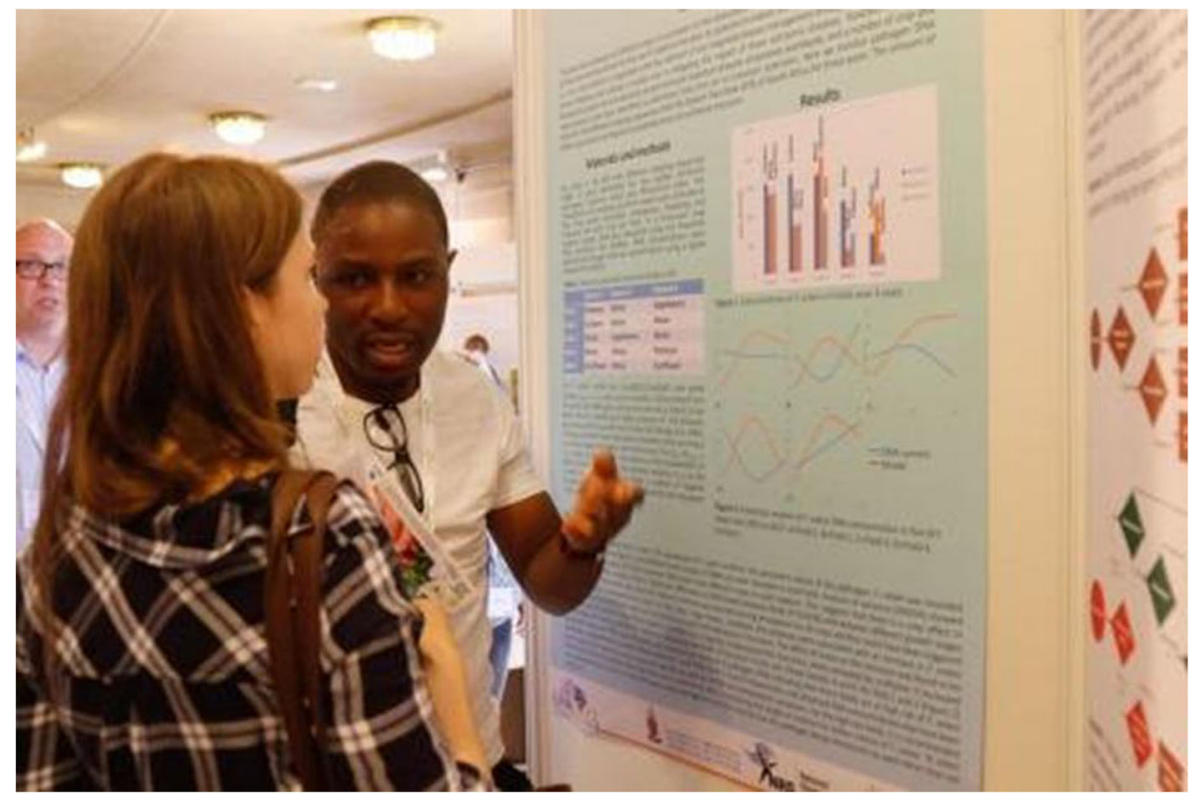

The seven mid-week trips included in the programme of the conference also contributed significantly to improve the international knowledge on the French production and marketing contexts and French research, scientific and technical establishments. Within a radius of $200 \mathrm{~km}$ around Versailles, the delegates were able to discover not only the research centres of INRA, ARVALIS and Comité Nord and development platforms (Qualipom, France Obtention), but also business structures in the fresh market (Parmentine, Pomly) or the processing sector (Tereos).

In addition to the scientific papers, the 20th Triennial EAPR Conference brought the official launch of the new logo and the new website of the Association: www.eapr.net. They replace the previous ones created more than 20 years ago. The current Council of the Association wanted this new impulse to allow creating a greater interactivity between the research teams to facilitate and enhance the exchange of knowledge for more accurate proposals to overcome the challenges of the industry.

This event, which celebrated the 60th anniversary of the Association, was also an opportunity for honouring as sustaining members two renowned scientists who have made a significant contribution to the technical improvement of the potato crop throughout their careers and demonstrated great commitment to the EAPR: Serge Duvauchelle (France) and Anton Haverkort (The Netherlands).

It is important not to forget the institutions, sponsors and partners of EAPR2017 who greatly helped to make this event possible in this worldwide renowned city of Versailles in a so appropriate congress centre. This place offered a conducive environment for 
sharing and networking in a cordial atmosphere. Without their support, the very good feedback received through the online survey about the conference would certainly have not been so good.

After France in 2017, it is now up to Poland to pick up the challenge of organising the 21st Conference of the EAPR in 2020, before Norway 3 years later. We bet that the Organising Committees that will be set up for these conferences will contribute again to position these EAPR triennial conferences at the level of world scientific exchanges!

Michel Martin

EAPR President 2014-2017 